\title{
Performance Analysis of a Shunt Compensator Controlled Using Modified Synchronous Reference Theory
}

\author{
Alka Singh \\ Department of Electrical Engineering, Delhi Technological University, Bawana Road, Delhi 110042, India \\ Correspondence should be addressed to Alka Singh; alkasingh.dr@gmail.com
}

Received 15 April 2014; Revised 2 July 2014; Accepted 2 July 2014; Published 7 August 2014

Academic Editor: José R. C. Piqueira

Copyright ( 2014 Alka Singh. This is an open access article distributed under the Creative Commons Attribution License, which permits unrestricted use, distribution, and reproduction in any medium, provided the original work is properly cited.

\begin{abstract}
This paper deals with the control of distribution energy resource (DER) connected to a grid connected system feeding nonlinear loads. The DER is controlled to provide power quality improvement capabilities, namely, power factor correction, harmonic reduction, and load balancing. The developed controller is based on modification of synchronous reference theory. It possesses unique features such as filtration and fundamental voltage extraction from the polluted grid voltages to eliminate harmonics and unbalance. Additionally, the control is implemented over the square of DC link voltage. The distributed generation source is realized as a voltage source converter. Both simulation and experimental results prove the effectiveness of control algorithm with nonlinear loads. The control algorithm works well for power factor correction, harmonic reduction, and operation under unbalanced load condition. The dynamics of the system under load change and load unbalancing are well depicted.
\end{abstract}

\section{Introduction}

A number of benefits of renewable energy resources exist, namely, high reliability, modular in nature, and environment friendly operation. These advantages have ensured increased acceptance of distributed resources in the world [1-12]. The renewable energy sources (wind, solar, etc.) are currently being interfaced to the conventional systems using voltage source inverters (VSCs) [2-4]. There are several advantages of distributed resources over conventional sources so a high emphasis is nowadays paid to renewable energy sources (RES) and their interconnection to grid. These sources are connected at the low or medium voltage levels. A primary energy source generally in the form of wind energy, photovoltaic cell, fuel cell, battery, and so forth is connected at the primary of the converter which converts this power and supplies it to the load in islanded mode. A number of such voltage source converters may be connected in parallel and to the utility grid also. Control of such distributed energy sources [5-13] is an important control aspect.

Very recently the concept of multifunctional distributed generators has been introduced which is controlled to provide two equally important tasks of providing power delivery as well as power quality improvement. Active power filters
$[1,12,14]$ provide reactive power compensation and power quality improvement only. The concept is to flexibly control the distributed generator resource as a source and extract maximum power from it and also provide compensation current from it. Lately, power converters in both voltage and current control mode $[7,8]$ have been used for utility interface for distributed generation sources. These converters are mainly interfaced with L or higher order LC/LCL filters [9-11]. Repetitive control, hysteresis regulation, and predictive control are frequently used and multiloop feedback control with LC/LCL filters is gaining popularity [4-11]. However, several points of concern relate to LCL filters, namely, the selection of the outer and inner control variables for improving system stability, avoiding resonance condition, and studying the effect on system performance under parameter variation. Figure 1 shows a number of distributed generation sources connected to the utility grid.

\section{System Description}

The diagram shows the distributed energy source feeding variety of loads (linear/nonlinear) in grid connected mode. A three-leg insulated gate bipolar transistors (IGBTs) based 


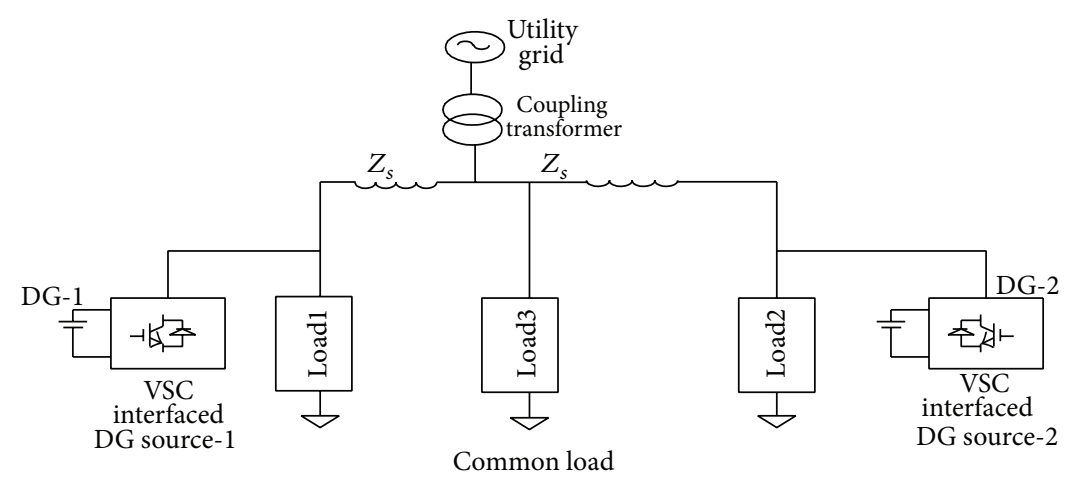

FIGURE 1: A number of distributed generation sources connected to utility grid.

VSC is used and controlled as DStatcom. It is connected to the point of common coupling (PCC) through a set of interfacing inductors $(R, L)$.

The implemented system requires VSC, interfacing inductors, scaling circuits for sensing the input signals, and driver circuit for output signals. Active power transfer flow can also take place by placing an active source (battery or renewable energy source) at DC link. Three Hall-effect current sensors (LEM LA 25-NP) are used to sense load currents for phases "A," "B," and "C." To sense the source currents for phases "A" and "B," another set of Hall-effect current sensors (LEM LA 25-NP) are used. The third phase source current is estimated by considering that the algebraic sum of three-phase source currents is zero. Two voltage sensors (LV 25-P) are used to sense phases " $\mathrm{A}$ " and " $\mathrm{B}$ " voltages. The third phase voltage is estimated considering the algebraic sum of three-phase source voltages is zero. The DC link voltage is sensed using the voltage sensor LV 25P/SP5. Scaling circuits are designed to use in between the sensed signals and ADC (analog to digital converter) of DSP to have a zero offset with the sensed signals. The control algorithm is realized in MATLAB environment with real time blocks. Hex codes are loaded in the DSP-dSPACE 1104 to generate six switching signals for IGBTs through PWM (pulse width modulation) pins of a DSP. A Semikron three-phase VSC (model MD B6CI 800/415-35F) with six IGBT based switches is used for experiments. Table 2 lists the parameters of the system used for simulation as well as experiments.

\section{Mathematical Model}

For the system configuration shown in Figure 2, $v_{t a}, v_{t b}$, and $v_{t c}$ denote the terminal voltages at the PCC and $v_{s a}, v_{s b}$, and $v_{s c}$ are the voltages at the three-phase ac source (grid); then the following differential equations can be written:

$$
\begin{gathered}
v_{s a}=v_{t a}-R_{s} i_{s a}-L_{s} \frac{d i_{s a}}{d t}, \\
v_{s b}=v_{t b}-R_{s} i_{s b}-L_{s} \frac{d i_{s b}}{d t}, \\
v_{s c}=v_{t c}-R_{s} i_{s c}-L \frac{d i_{s c}}{d t} .
\end{gathered}
$$

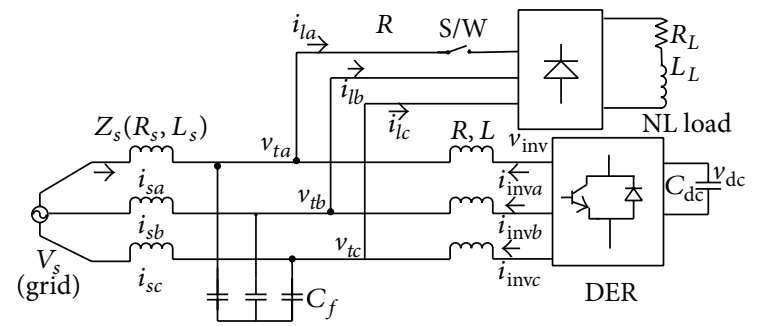

FIGURE 2: Schematic diagram of utility grid and distributed energy source feeding loads.

The equations relating the inverter voltages with the PCC voltages are written as

$$
\begin{aligned}
& v_{t a}=v_{\text {inva }}-R i_{\text {inva }}-L \frac{d i_{\text {inva }}}{d t}, \\
& v_{t b}=v_{\text {inv } b}-R i_{\text {inv } b}-L \frac{d i_{\text {inv }}}{d t}, \\
& v_{t c}=v_{\text {invc }}-R i_{\text {invc }}-L \frac{d i_{\text {invc }}}{d t},
\end{aligned}
$$

where $R, L$ denote the interfacing resistor and inductor values and $i_{\text {inv } a}, i_{\text {inv } b}$, and $i_{\text {invc }}$ and $v_{\text {inv } a}, v_{\text {inv } b}$, and $v_{\text {invc }}$ denote the inverter currents and voltages in three phases. At the DC link (3) is valid:

$$
\frac{C d v_{\mathrm{dc}}}{d t}=i_{\mathrm{dc}}
$$

The equations shown above can be depicted in the form of a single closed loop control for the control of grid current $\left(i_{s}\right)$ as shown in Figure 3.

The PWM inverter is represented as $K_{\text {inv }} /\left(1+s T_{\text {inv }}\right) ; R$ and $L$ represent the interfacing resistance and inductance, respectively. For further simplification $T_{\text {inv }}=0$.

The current controller is represented in the form of PI controller with transfer function:

$$
G c(s)=K_{p}+\left(\frac{K_{i}}{s}\right)
$$




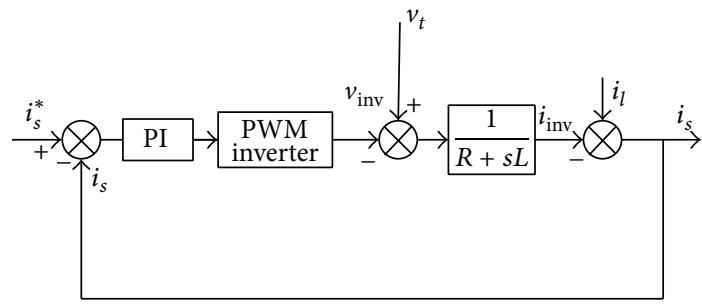

FIgURE 3: Simplified closed loop analysis of the system.

The closed loop transfer function is derived to be

$$
\frac{i_{s}}{i_{s}^{*}}=\frac{K_{\mathrm{inv}}\left(K_{p} s+K_{i}\right)}{s^{2} L+s\left(R+K_{\mathrm{inv}} K_{p}\right)+K_{\mathrm{inv}} K_{i}} .
$$

Comparing with the standard closed loop transfer function, we get

$$
\frac{i_{s}}{i_{s}^{*}}=\frac{w_{n}^{2}}{s^{2}+2 s \zeta w_{n}+w_{n}^{2}} .
$$

The values of damping ratio $\zeta$ and angular frequency $w_{n}$ are found to be influenced by parameters $K_{p}, K_{i}$, and $K_{\text {inv }}$ and parameters $R$ and $L$. The desired damping ratio is obtained by varying the gain constants.

\section{Control Algorithm}

The control algorithm used for the control of distributed generation source in this paper is based on modified synchronous reference frame theory. The synchronisation is achieved by deriving unit templates from the supply grid. Since, it is observed that the supply voltages have harmonics and are unbalanced, hence, the use of filters and extraction of fundamental voltage component of the three phases are undertaken as a preliminary step. These filtered supply voltages are used as PCC voltages for the generation of reference current generation as is discussed below. Figure 4 shows the control algorithm developed using synchronous reference frame (SRF) theory. A noticeable difference is that the control is developed over the square of DC link voltage. Although the DC link voltage is sensed, the PI controller is developed over the error between the actual and reference value of square of DC link voltage. The SRF based controller utilizes the $a b c-d q$ transformation (Park's transformation) to transform the current and voltage waveforms into a reference frame that rotates synchronously with the grid voltage.

Filtered fundamental PCC voltages $\left(v_{s a f}, v_{s b f}\right.$, and $\left.v_{s c f}\right)$ are obtained by filtering voltages $\left(v_{s a}, v_{s b}\right.$, and $\left.v_{s c}\right)$ through band pass filters, whose cutoff frequency is between $30 \mathrm{~Hz}$ and $60 \mathrm{~Hz}$. The symmetrical component method developed by Akagi et al. [1] is used to obtain fundamental voltage components $\left(v_{s a 1}, v_{s b 1}\right.$, and $\left.v_{s c 1}\right)$ from the filtered voltages as below:

$$
\begin{aligned}
& v_{s a 1}=\frac{1}{3}\left(v_{s a f}+\lambda v_{s b f}+\lambda^{2} v_{s c f}\right), \\
& v_{s b 1}=\frac{1}{3}\left(v_{s b f}+\lambda a v_{s c f}+\lambda^{2} v_{s a f}\right), \\
& v_{s c 1}=\frac{1}{3}\left(v_{s c f}+\lambda v_{s a f}+\lambda^{2} v_{s b f}\right),
\end{aligned}
$$

where $\lambda=e^{j 120}=-0.5+0.866 j$ and $\lambda^{2}=e^{j 240}=-0.5-$ $0.866 j$.

The amplitude of the PCC voltage is now obtained using

$$
V_{t m}=\left\{\frac{2}{3}\left(v_{s a 1}{ }^{2}+v_{s b 1}^{2}+v_{s c 1}{ }^{2}\right)\right\}^{1 / 2} .
$$

The unit in-phase vectors $\left(u_{a}, u_{b}\right.$, and $\left.u_{c}\right)$ are calculated as

$$
\begin{aligned}
& u_{a}=\frac{v_{s a 1}}{V_{t m}}, \\
& u_{b}=\frac{v_{s b 1}}{V_{t m}}, \\
& u_{c}=\frac{v_{s c 1}}{V_{t m}} .
\end{aligned}
$$

The quadrature unit current vectors $\left(w_{a}, w_{b}\right.$, and $\left.w_{c}\right)$ are derived from in-phase unit current $\left(u_{a}, u_{b}\right.$, and $\left.u_{c}\right)$ vectors as

$$
\begin{gathered}
w_{a}=\frac{\left(-u_{b}+u_{c}\right)}{\left\{(3)^{1 / 2}\right\}}, \\
w_{b}=\frac{\left(u_{a}(3)^{1 / 2}+\left(u_{b}-u_{c}\right)\right)}{\left\{2(3)^{1 / 2}\right\}}, \\
w_{c}=\frac{\left(-u_{a}(3)^{1 / 2}+\left(u_{b}-u_{c}\right)\right)}{\left\{2(3)^{1 / 2}\right\}} .
\end{gathered}
$$

The basic SRF theory involves the transformation of currents in synchronously rotating $d-q$ frame. It uses the PLL block to evaluate $\theta$ and transformation angle to convert currents from $\alpha \beta$ to $d q$ frame:

$$
\begin{aligned}
& i_{\alpha}=i_{l a}\left(\sqrt{\frac{2}{3}}\right) \cos \theta-i_{l b}\left(\sqrt{\frac{1}{6}}\right)-i_{l c}\left(\sqrt{\frac{1}{6}}\right), \\
& i_{\beta}=i_{l b}\left(\sqrt{\frac{1}{2}}\right)-i_{l c}\left(\sqrt{\frac{1}{2}}\right), \\
& i_{d}=i_{\alpha} \cos \theta+i_{\beta} \sin \theta, \\
& i_{q}=-i_{\alpha} \sin \theta+i_{\beta} \cos \theta .
\end{aligned}
$$

Instead of the PLL block, the unit templates obtained from filtered PCC voltages are used to estimate $i_{d}, i_{q}$ values of load currents. The obtained $i_{d}$ and $i_{q}$ currents are now passed over 


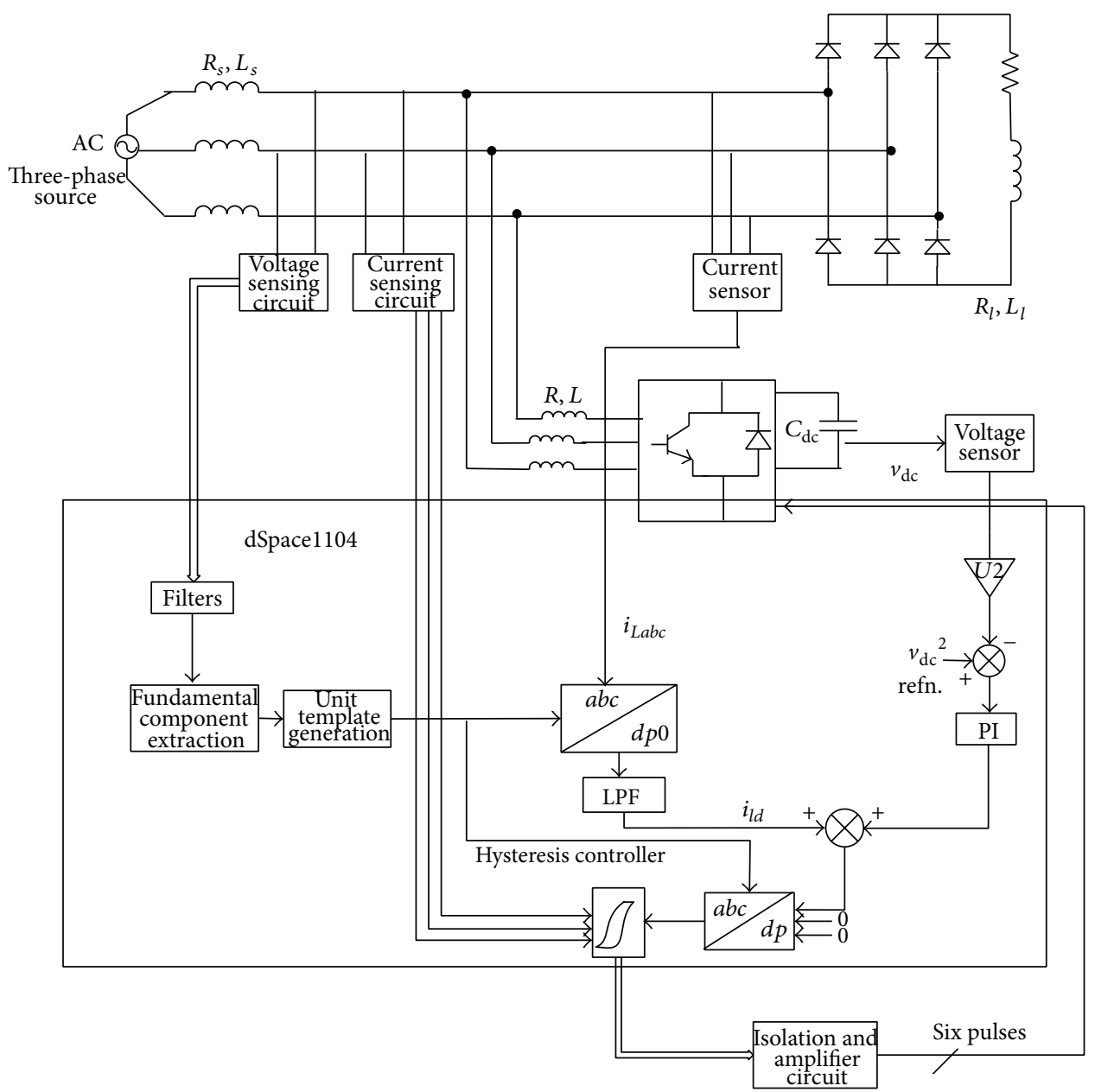

Figure 4: Complete control scheme for the system.

low pass filter (LPF) to extract the dc components $i_{d \mathrm{dc}}$ and $i_{q \mathrm{dc}}$. A PI controller is realised over the square of DC link voltage to regulate it to its reference value:

$$
i_{d(n)}=i_{d(n-1)}+K_{p d}\left\{v_{\mathrm{dcl}}^{2}(n)-v_{\mathrm{dc} 1}^{2}(n-1)\right\}+K_{i d} v_{\mathrm{dc} 1}(n)
$$

where $v_{\mathrm{dcl}}(n)=v_{\mathrm{dcref}}^{2}(n)-v_{\mathrm{dc}}^{2}(n)$ denotes the error in square of DC link voltage calculated over reference and sensed value obtained from the voltage sensor. $K_{p d}$ and $K_{i d}$ are the proportional and integral gains of the PI controller. The output of PI controller accounts for the losses of VSC and this component is added to the $i_{d \mathrm{dc}}$ for power factor correction.

Once the reference $d, q$ components of currents are obtained, the three-phase reference supply currents $\left(i_{s a r}, i_{s b r}\right.$, and $\left.i_{s c r}\right)$ can be obtained. These reference supply currents are compared with the sensed supply currents $\left(i_{s a}, i_{s b}\right.$, and $\left.i_{s c}\right)$ to estimate the three-phase current error components. The current errors are passed over carrier-less PWM controller to generate gating signals for the six IGBTs (insulated gate bipolar transistors) of VSC. The control scheme is direct and based on supply (grid) currents instead of the inverter currents in the three phases.

\section{Performance and Results}

A MATLAB based model of distributed energy resource is developed and tested under distorted and unbalanced voltage of ac mains to validate the proposed control algorithm. The performance of modified synchronous detection control algorithm in time domain is simulated and analyzed using a three-leg VSC configuration with nonlinear loads. Simulations as well as experimental results are presented for two cases, namely, power factor correction and load balancing along with power factor correction.

5.1. Power Factor Correction and Load Change. Figure 5 shows the simulated results showing the filtered PCC voltage $\left(v_{t}\right)$, supply currents $\left(i_{s}\right)$, load currents $\left(i_{l}\right)$, currents $\left(i_{c}\right)$ injected by DStatcom, and DC link voltage $\left(v_{\mathrm{dc}}\right)$. The results are obtained with a nonlinear load of $R_{l}=30 \Omega$ connected at the end of diode rectifier. Load is varied to $R_{l}=50 \Omega$ for time duration from $t=0.2 \mathrm{sec}$ to $t=0.28 \mathrm{sec}$. The dynamics of the currents and DC link are evident from Figure 5 and it is observed that the DC link voltage settles down to a reference value of $200 \mathrm{~V}$ in less than two cycles. The THD of the supply currents is $4.3 \%$ when the load currents have a THD of $28 \%$. 


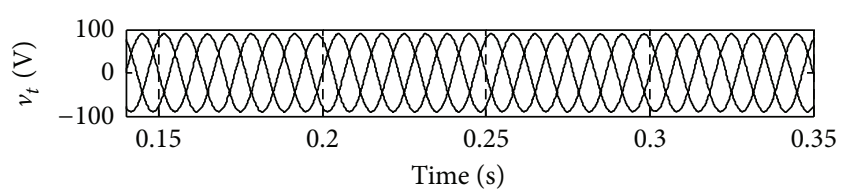

(a)

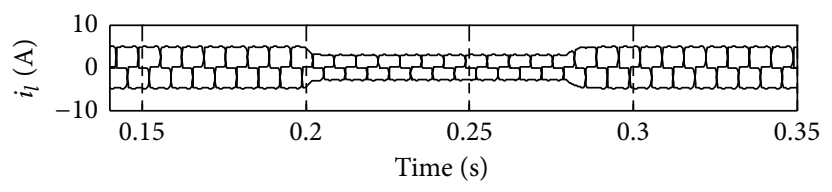

(c)

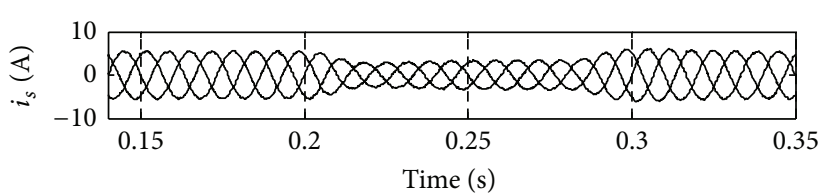

(b)

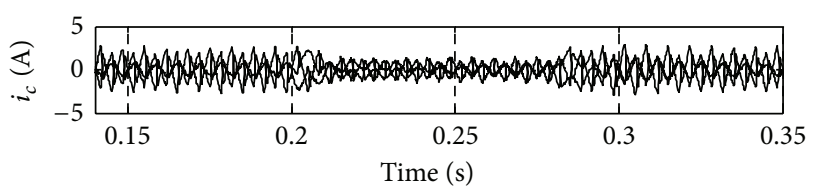

(d)

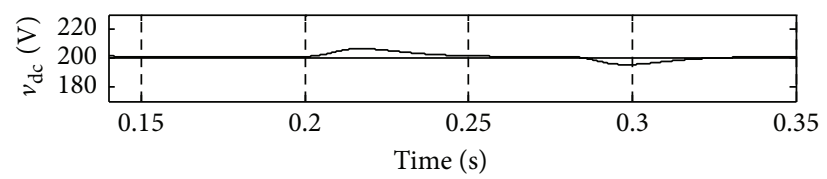

(e)

FIGURE 5: Simulated results for power factor correction in steady state as well as load removal $(t=0.2 \mathrm{sec})$ and addition $(t=0.28 \mathrm{sec})$.

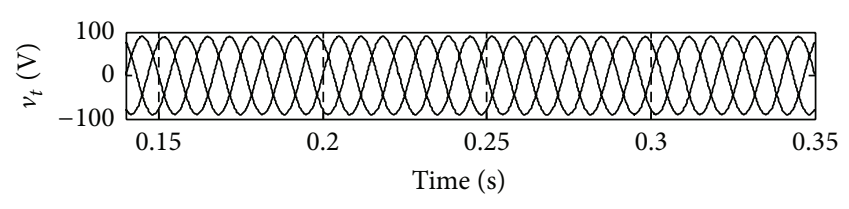

(a)

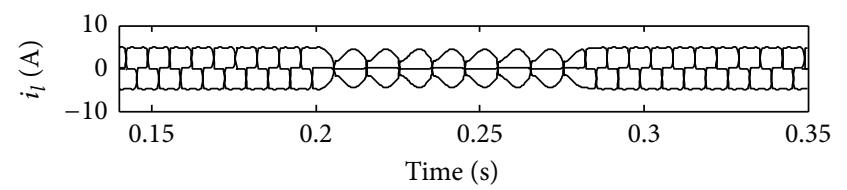

(c)

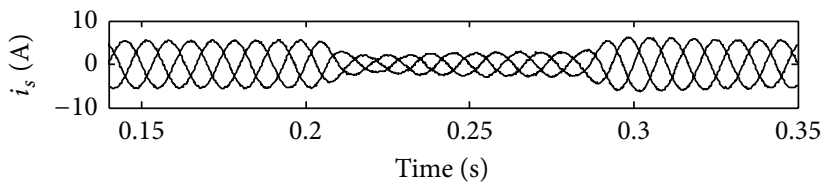

(b)

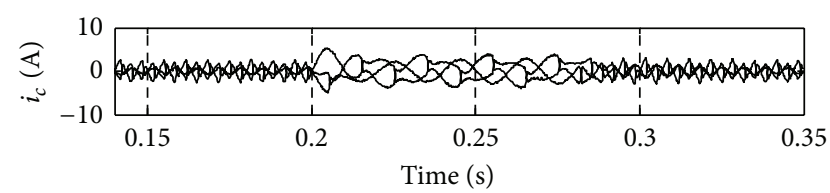

(d)

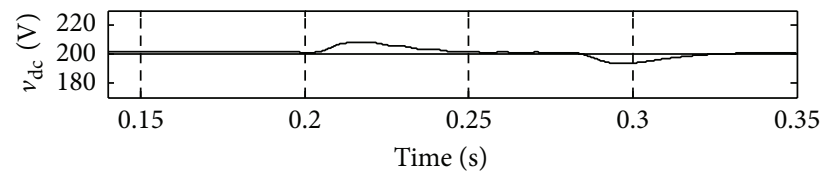

(e)

FiguRE 6: Simulated results for power factor correction and load balancing in steady state as well as one phase load removal ( $t=0.2 \mathrm{sec})$ and restoration $(t=0.28 \mathrm{sec})$.

5.2. Power Factor Correction under Unbalanced Load Operation. Figure 6 shows the simulated results for the system under steady state conditions till $t=0.2 \mathrm{sec}$ when phase " $c$ " of the load is suddenly disconnected from $t=0.2 \mathrm{sec}$ to $t=0.28 \mathrm{sec}$. The simulated results show that the control algorithm not only maintains the DC link voltage but also the grid currents are balanced and sinusoidal during this interval. The distributed energy source works as a shunt compensator and injects compensating currents of higher magnitude now and this can be observed from the simulation results. The normal balanced loads with $R_{l}=30 \Omega$ and $L=60 \mathrm{mH}$ are restored at $t=0.28 \mathrm{sec}$. The THD of the supply currents is $4.4 \%$ when the load currents have a THD of $29 \%$.

\section{Experimental Results for Proposed Scheme}

The experimental results for the same system configuration (shown in Table 2) and load are shown in Figures 7 and 8. Figure 7(a) shows the waveforms of phase "a" supply current, load current, compensator current, and Dc link voltage in steady state.

Figures 7(b) and 7(c) show the dynamics of load decrease and load increase, respectively. Figure 8(a) shows the Power Analyser 434 (Fluke) waveforms and THD of the supply current which is $4.4 \%$. The unfiltered PCC voltages are depicted in Figure 8(b) that show a THD of $2.8 \%$ and the magnitudes are also slightly different. It is due to this reason only that filtered, positive sequence voltage components 


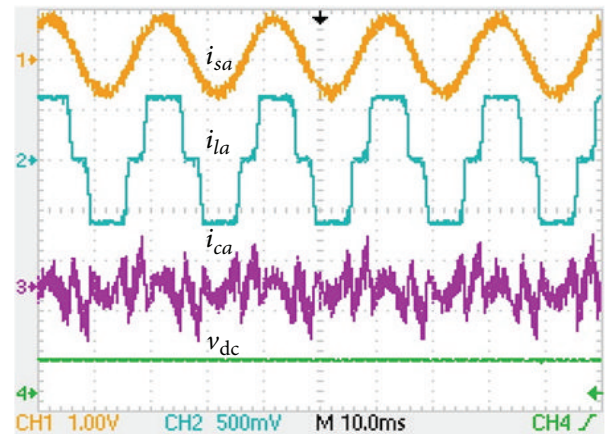

(a)

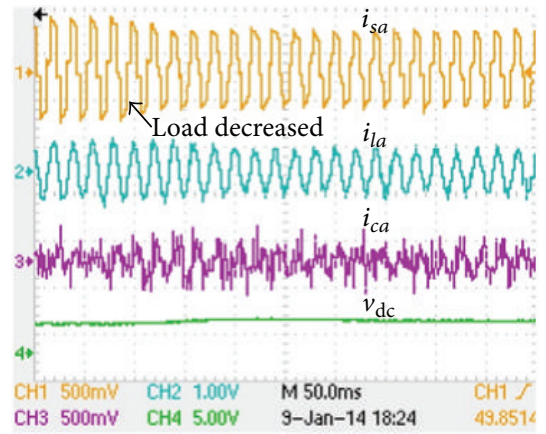

(b)

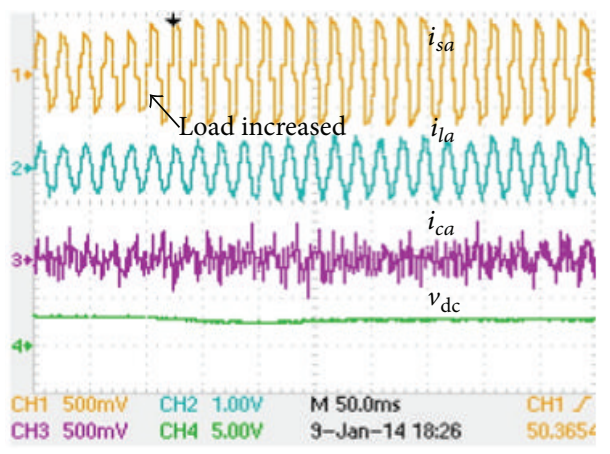

(c)

Figure 7: (a) Plot of $i_{s a}, i_{l a}, i_{c a}, V_{\mathrm{dc}}\left(10 \mathrm{~A} / \mathrm{div}, 5 \mathrm{~A} / \mathrm{div}, 5 \mathrm{~A} / \mathrm{div}\right.$ for the currents). (b) Plot of $i_{l a}, i_{l b}, i_{l c}, V_{\mathrm{dc}}(5 \mathrm{~A} / \mathrm{div}, 5 \mathrm{~A} / \mathrm{div}, 5 \mathrm{~A} / \mathrm{div}$ for the currents) for load decrease. (c) Plot of $i_{l a}, i_{l b}, i_{l c}, V_{\mathrm{dc}}(5 \mathrm{~A} / \mathrm{div}, 5 \mathrm{~A} / \mathrm{div}, 5 \mathrm{~A} / \mathrm{div}$ for the currents) for load increase.
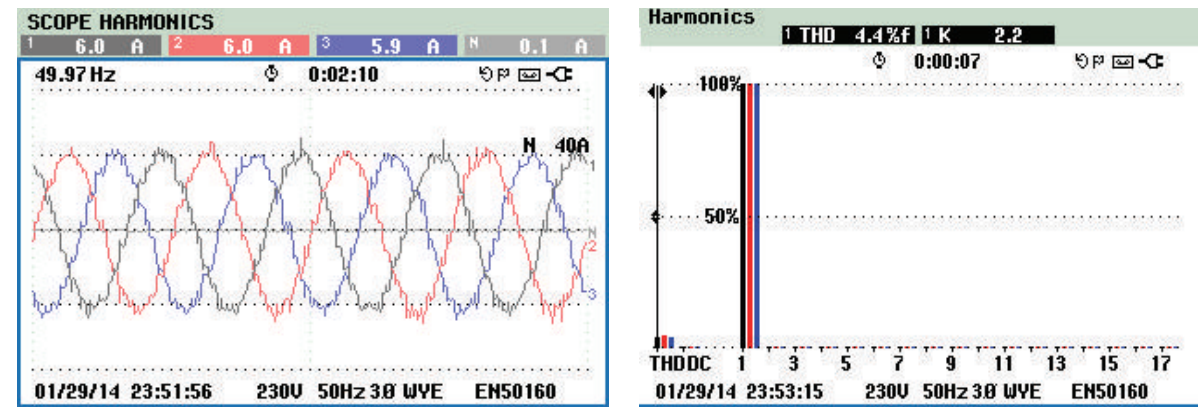

(a)
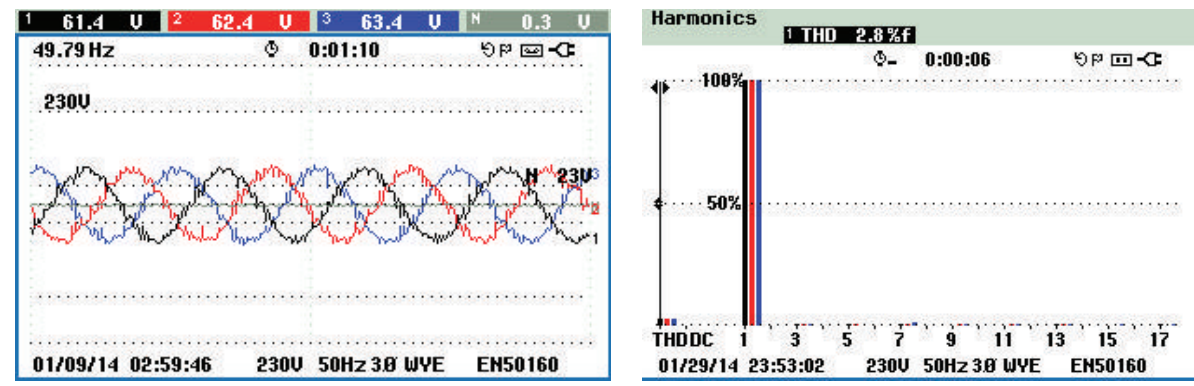

(b)

Figure 8: (a) Fluke 434 results showing three-phase supply currents $\left(i_{s a}, i_{s b}, i_{s c}\right)$ and THD of $4.4 \%$. (b) Supply voltages showing $2.8 \%$ THD. 


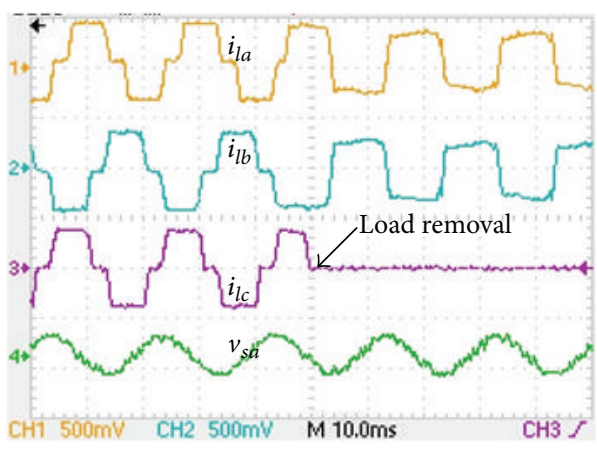

(a)

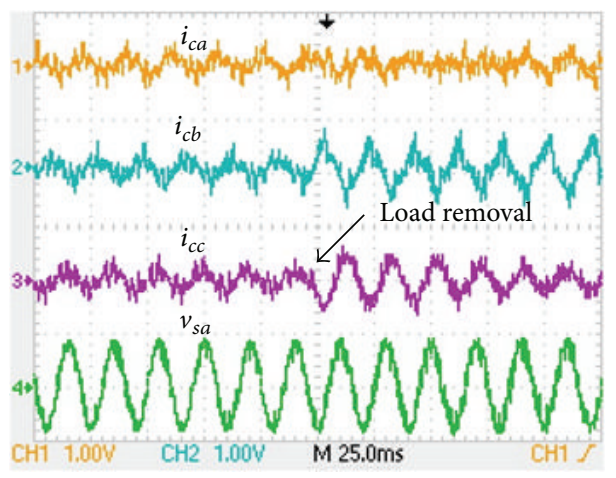

(c)

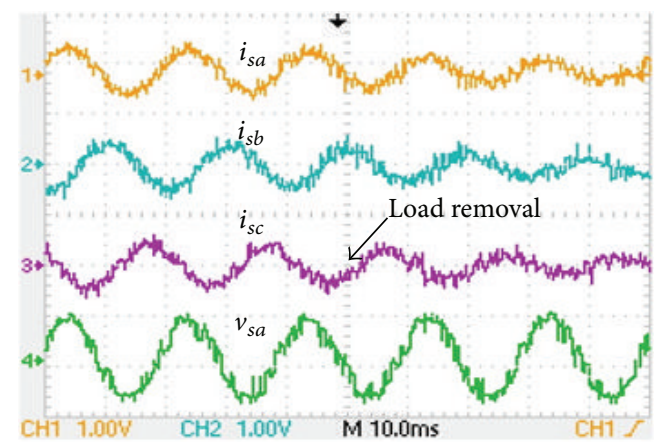

(b)

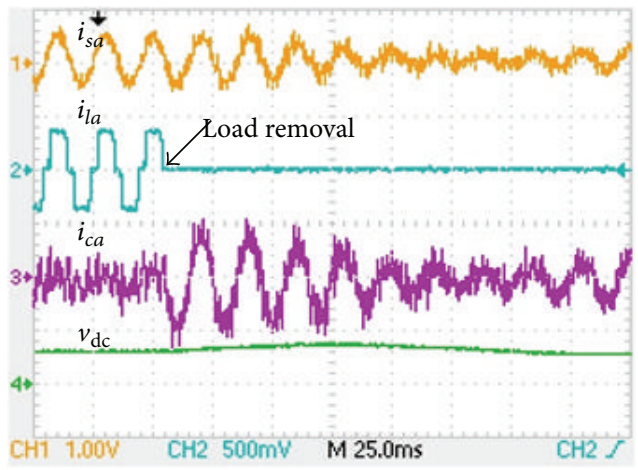

(d)

Figure 9: (a) Load current $s(5 \mathrm{~A} / \mathrm{div})$ and $v_{s a}$. (b) Supply voltages $(5 \mathrm{~A} / \mathrm{div})$ and $v_{s a}$. (c) Inverter currents $(5 \mathrm{~A} / \mathrm{div})$ and $v_{s a}$. (d) Source, load, inverter currents $(5 \mathrm{~A} / \mathrm{div})$, and DC link voltage.

are first extracted and then used for further analysis and reference current generation.

Experimental verification for power factor correction and load unbalancing are presented next in Figure 9. The load current in phase "c" is suddenly disconnected and this is evident from the plot Figure 9(b) for ilc. Figure 9(c) shows the variation of grid supply currents in all the three phases before and after the instant of unbalancing.

Figure 9(c) shows the variation of compensator currents in all the three phases before and after load in phase " $\mathrm{c}$ " is disconnected for some time. It is observed from Figures 9(a)-9(c) that the distributed source is controlled to provide necessary compensation currents during unbalanced load conditions. The DER acts as a shunt compensator and regulates the grid currents to be equal, balanced, and sinusoidal even when one phase of load is switched off. It provides large compensation currents in all the three phases during the interval. Also, it is observed from Figure 9(d) that the DC link settles down to its reference value of $200 \mathrm{~V}$ quite rapidly.

\section{Result Comparison}

Conventional SRF scheme has a few drawbacks; namely, it cannot be used to obtain optimum results under unbalanced grid supply voltages. The voltage signals are processed by the PLL to generate $\theta$. This transformation angle $(\theta)$ is sensitive to voltage harmonics and unbalances. Hence, filtered PCC voltages are used in the modified control algorithm for reference current generation. If the unfiltered voltages are used in control algorithm, the reference supply currents generated would themselves be nonsinusoidal and it would be difficult to achieve three-phase sinusoidal, balanced supply currents. The use of positive, negative, and zero sequence components has been used in this paper, which is simple and effective method for extraction.

The processing of current signals in both the schemes is similar. These are transformed into $d-q$ frame and then filtered. Then, compensating current is transformed back to $a-b-c$ frame and fed to hysteresis current controller for switching pulse generation. The results obtained show that under normal operating conditions, both the control strategies are suitable for compensation, but under the distorted supply conditions and unbalanced operating condition, the performance of the conventional scheme deteriorates. The experimental results for the conventional scheme are shown in Figure 10.

Figure 10 shows the results with conventional SRF scheme. It is evident that the supply voltages have a high THD level of 3.6\% (Figure 10(f)). With the controller realised on $v_{\mathrm{dc}}$ and the gains optimised, the performance of the shunt compensator is observed. The load current has a high THD content of $23.5 \%$, the controller injects compensating currents to make the supply current sinusoidal. Under the optimised PI gains, the lowest THD observed in supply currents is of the order of $4.8 \%$. This is higher than the THD level of $4.4 \%$ observed with the $v_{\mathrm{dc}}^{2}$ controller and the modified SRF 


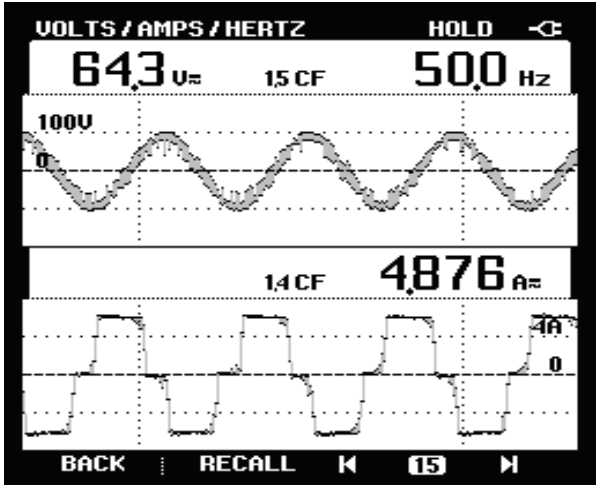

(a)

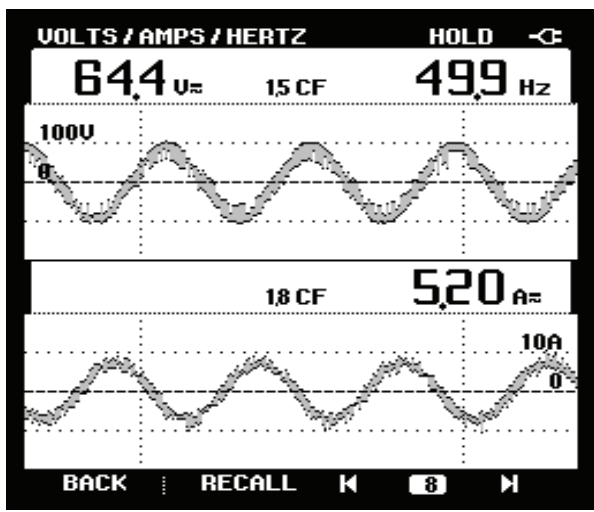

(c)

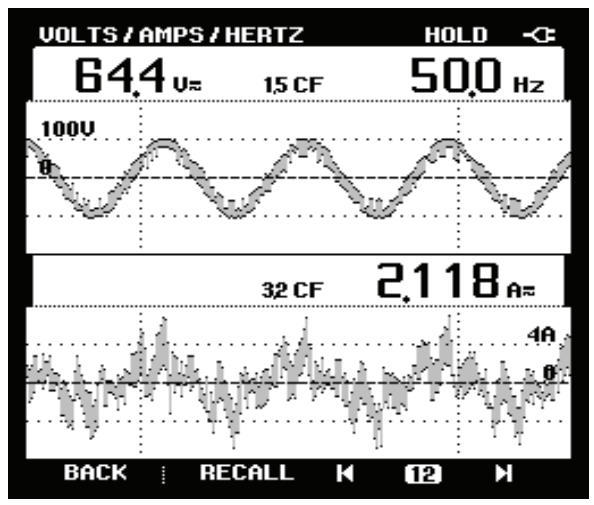

(e)

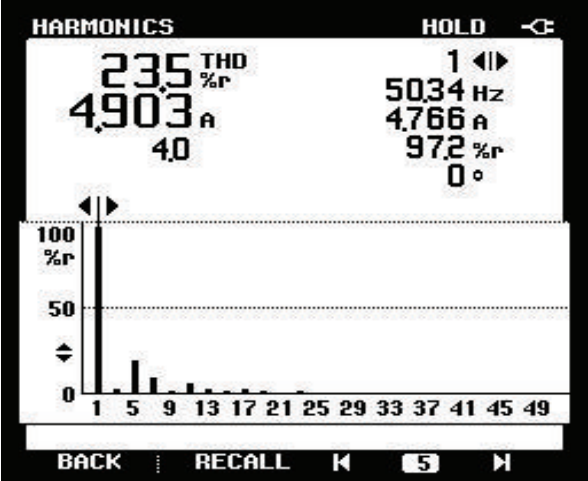

(b)

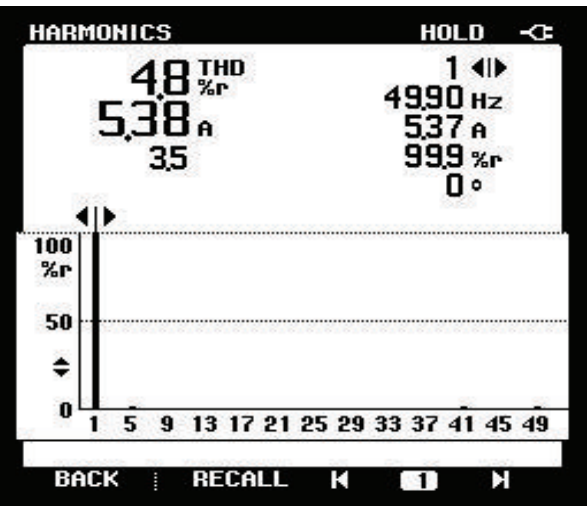

(d)

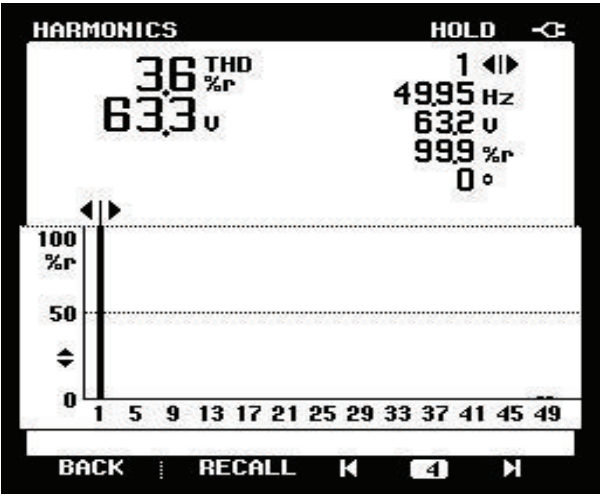

(f)

Figure 10: (a, b) $v_{s a}$ and load current $\left(i_{l a}\right)(5 \mathrm{~A} / \mathrm{div})$ and its THD $23.5 \%$. (c, d) $v_{s a}$ and supply current $\left(i_{s a}\right)(5 \mathrm{~A} / \mathrm{div})$ and its THD $4.8 \%$. (e) $v_{s a}$ and compensator current $\left(i_{c a}\right)(5 \mathrm{~A} / \mathrm{div})$. (f) THD $3.6 \%$ in the grid voltage.

theory. Figures 11 and 12 show the waveforms and THD for $i_{s a}$, $i_{l a}$ with modified SRF theory, and conventional SRF theory, respectively. Figures 11 and 12 show the simulation results with both the schemes and Table 1 highlights the comparison between the two schemes.

Comparison results are highlighted in Table 1.

\section{Conclusions}

This paper discusses and implements a control algorithm based on modification of synchronous reference frame theory for interfacing a distributed energy source to grid. The control algorithm is investigated to inject only reactive power and relieve the grid from supplying it. The control scheme is modified to include fundamental voltage component of the PCC voltage which is having harmonics, and unbalancing of up-to $5 \%$. A single closed loop control for the system is investigated for control of grid currents. The control is developed and experimentally tested on $v_{\mathrm{dc}}^{2}$ rather than the usual control on $v_{\mathrm{dc}}$ alone. Two benefits, namely, lower possible reduction in THD level and lower range of PI controller gain settings, were observed with this control. Simulation 


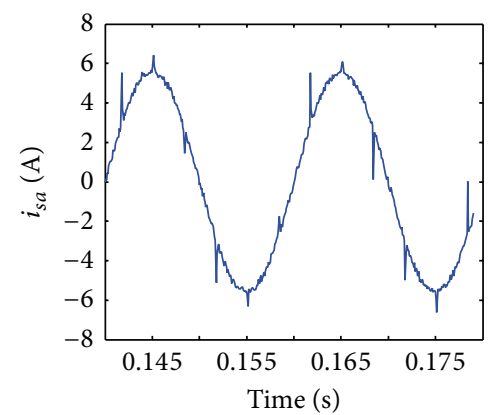

(a)

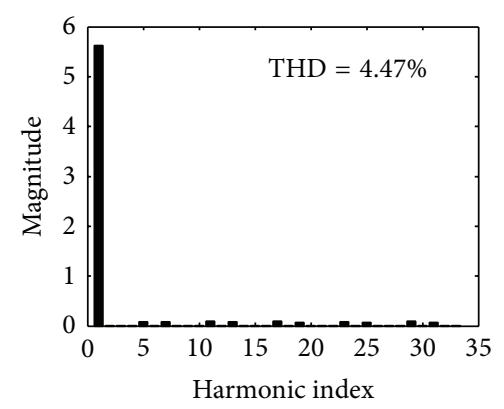

(c)

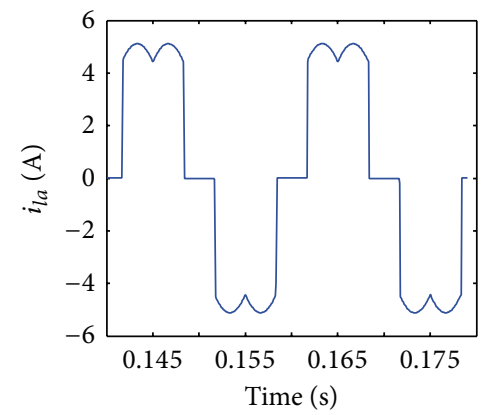

(b)

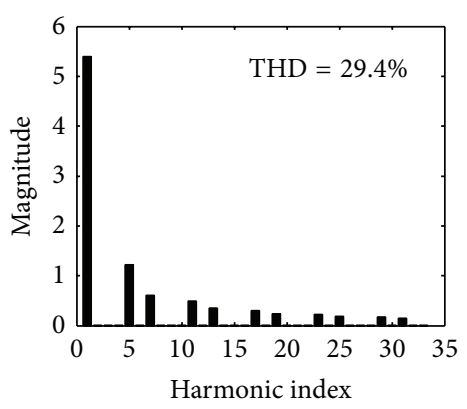

(d)

FIGURE 11: Waveforms and THD for $i_{s a}$ and $i_{l a}$ for modified SRF theory.

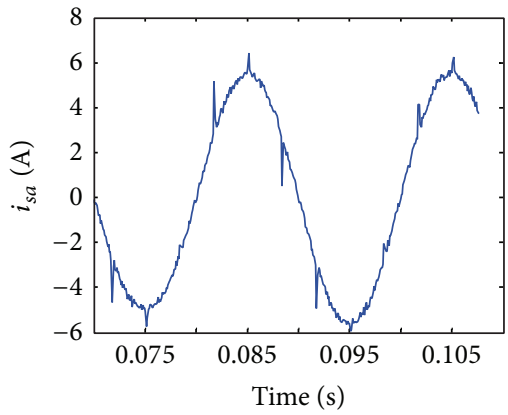

(a)

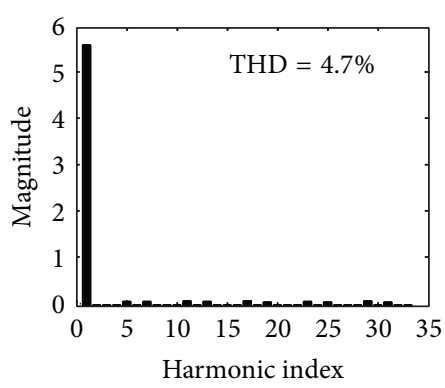

(c)

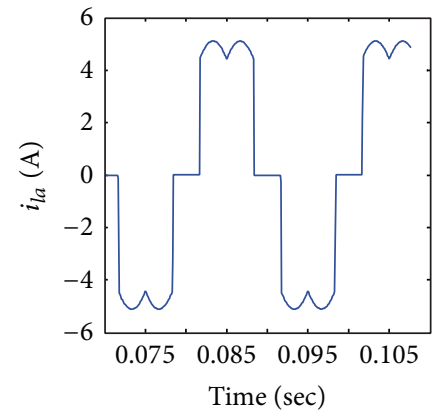

(b)

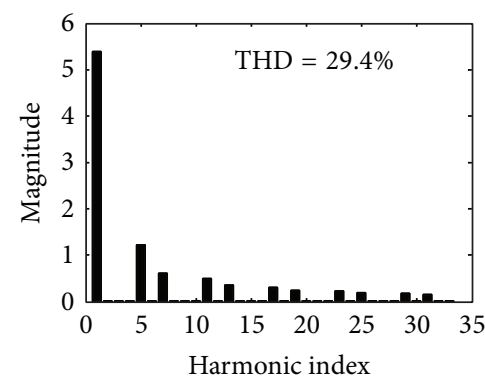

(d)

FIGURE 12: Waveforms and THD for $i_{s a}$ and $i_{l a}$ for conventional SRF theory.

TABLE 1: Comparison of Control schemes.

\begin{tabular}{lccccc}
\hline & Parameters (Kp, Ki) & Overshoot (V) & Undershoot (V) & Settling Time (sec) & THD \\
\hline Conventional SRF & $0.35,0.1$ & $\sim 3 \mathrm{~V}$ & $\sim 2 \mathrm{~V}$ & $<2$ cycles & $4.9 \%$ approx \\
Modified SRF & $0.00028,0.00034$ & $\sim 4 \mathrm{~V}$ & $\sim 3 \mathrm{~V}$ & $<2$ cycles & $4.5 \%$ approx \\
\hline
\end{tabular}


TABLE 2: System parameters (Both Simulation and Experimental).

\begin{tabular}{lc}
\hline Parameters & Value \\
\hline Grid voltage $E(\mathrm{RMS})$ & $63.5 \mathrm{~V}$ \\
DC-link voltage $V_{\mathrm{dc}}$ & $200 \mathrm{~V}$ \\
DC link capacitor $C_{\mathrm{dc}}$ & $1600 \mu \mathrm{F}$ \\
Inverter-side filter $L$ & $3.5 \mathrm{mH}$ \\
Filter capacitor $C_{f}$ & $3 \mu \mathrm{F}$ \\
Rectifier resistor $R_{l}$ & $30 \Omega$ \\
Load Inductor $L_{l}$ & $60 \mathrm{mH}$ \\
Sampling frequency $f_{s}$ & $10 \mathrm{kHz}$ \\
\hline
\end{tabular}

results and experimental results for the prototype system are obtained for power factor correction, load unbalancing, and reduction of THD in grid currents. The experimental results obtained are very close to the simulation results. The proposed control scheme is able to achieve a THD of $4.4 \%$ in grid currents when the load current is $28.7 \%$, thus meeting IEEE 519 standards. The distribution shunt compensator has been utilized to provide reactive power compensation only, though real power injection into the system is also possible with an active source at the DC link.

\section{Conflict of Interests}

The author declares that there is no conflict of interests regarding the publication of this paper.

\section{Acknowledgment}

The author wishes to thank the Department of Science and Technology, Government of India, for the sponsored Project no. SR/FTP/ETA-20/2010.

\section{References}

[1] H. Akagi, E. H. Watanabe, and M. Aredes, Instantaneous Power Theory and Applications to Power Conditioning, IEEE Press, Wiley InterScience, 2007.

[2] F. Blaabjerg, Z. Chen, and S. B. Kjaer, "Power electronics as efficient interface in dispersed power generation systems," IEEE Transactions on Power Electronics, vol. 19, no. 5, pp. 1184-1194, 2004.

[3] C. K. Duffey and R. P. Stratford, "Update of harmonic standard IEEE-519: IEEE recommended practices and requirements for harmonic control in electric power systems," IEEE Transactions on Industry Applications, vol. 25, no. 6, pp. 1025-1034, 1989.

[4] R. Teodorescu, M. Liserre, and P. Rodríguez, Grid Converters for Photovoltaic and Wind Power Systems, John Wiley \& Sons, New York, NY, USA, 2011.

[5] F. Blaabjerg, R. Teodorescu, M. Liserre, and A. V. Timbus, "Overview of control and grid synchronization for distributed power generation systems," IEEE Transactions on Industrial Electronics, vol. 53, no. 5, pp. 1398-1409, 2006.

[6] I. Chung, W. Liu, D. A. Cartes, and E. G. Collins, "Control methods of inverter-interfaced distributed generators in a microgrid system," IEEE Transactions on Industry Applications, vol. 46, no. 3, pp. 1078-1088, 2010.
[7] J. He, Y. W. Li, and M. S. Munir, "A flexible harmonic control approach through voltage-controlled DG-grid interfacing converters," IEEE Transactions on Industrial Electronics, vol. 59, no. 1, pp. 444-455, 2012.

[8] J. He and Y. W. Li, "Hybrid voltage and current control approach for dg-grid interfacing converters with LCL filters," IEEE Transactions on Industrial Electronics, vol. 60, no. 5, pp. 1797-1809, 2013.

[9] P. C. Loh and D. G. Holmes, "Analysis of multiloop control strategies for LC/CL/LCL-filtered voltage-source and currentsource inverters," IEEE Transactions on Industry Applications, vol. 41, no. 2, pp. 644-654, 2005.

[10] J. He and Y. W. Li, "Generalized closed-loop control schemes with embedded virtual impedances for voltage source converters with LC or LCL filters," IEEE Transactions on Power Electronics, vol. 27, no. 4, pp. 1850-1861, 2012.

[11] N. He, D. Xu, Y. Zhu et al., "Weighted average current control in a three-phase grid inverter with an LCL filter," IEEE Transactions on Power Electronics, vol. 28, no. 6, pp. 2785-2797, 2013.

[12] Y. Li, D. M. Vilathgamuwa, and P. C. Loh, "Microgrid power quality enhancement using a three-phase four-wire gridinterfacing compensator," IEEE Transactions on Industry Applications, vol. 41, no. 6, pp. 1707-1719, 2005.

[13] D. N. Zmood and D. G. Holmes, "Stationary frame current regulation of PWM inverters with zero steady-state error," IEEE Transactions on Power Electronics, vol. 18, no. 3, pp. 814-822, 2003.

[14] A. Chandra, B. Singh, B. N. Singh, and K. Al-Haddad, "An improved control algorithm of shunt active filter for voltage regulation, harmonic elimination, power-factor correction, and balancing of nonlinear loads," IEEE Transactions on Power Electronics, vol. 15, no. 3, pp. 495-507, 2000. 

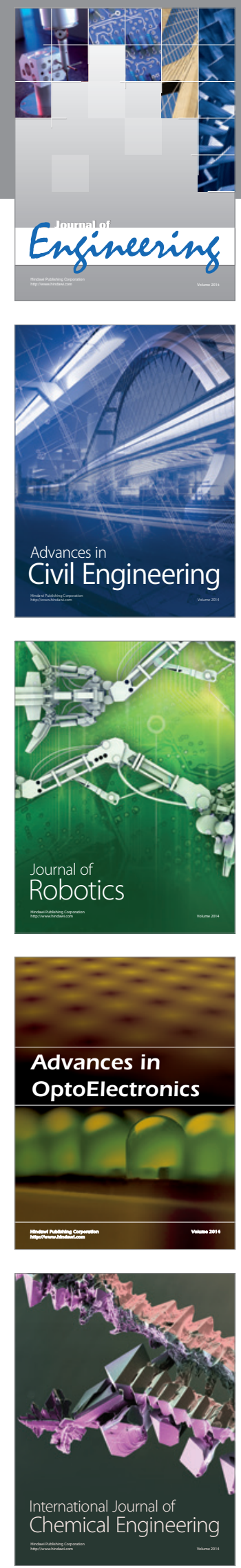

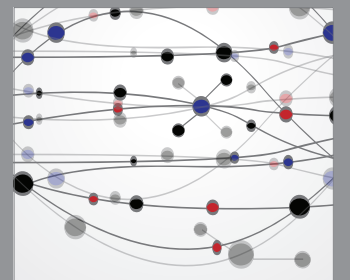

The Scientific World Journal
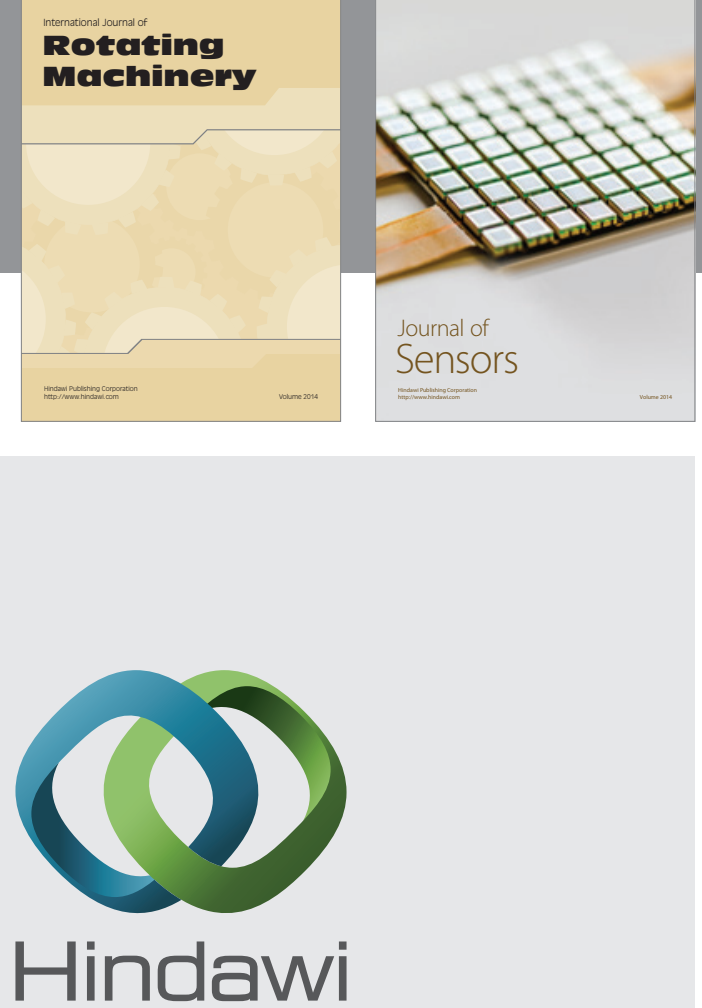

Submit your manuscripts at http://www.hindawi.com
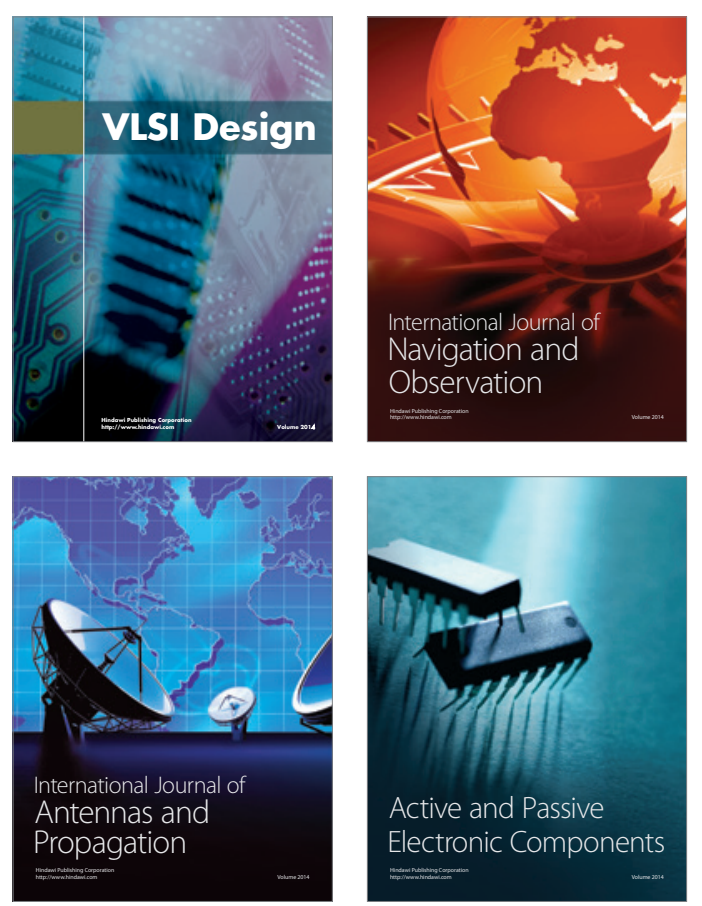
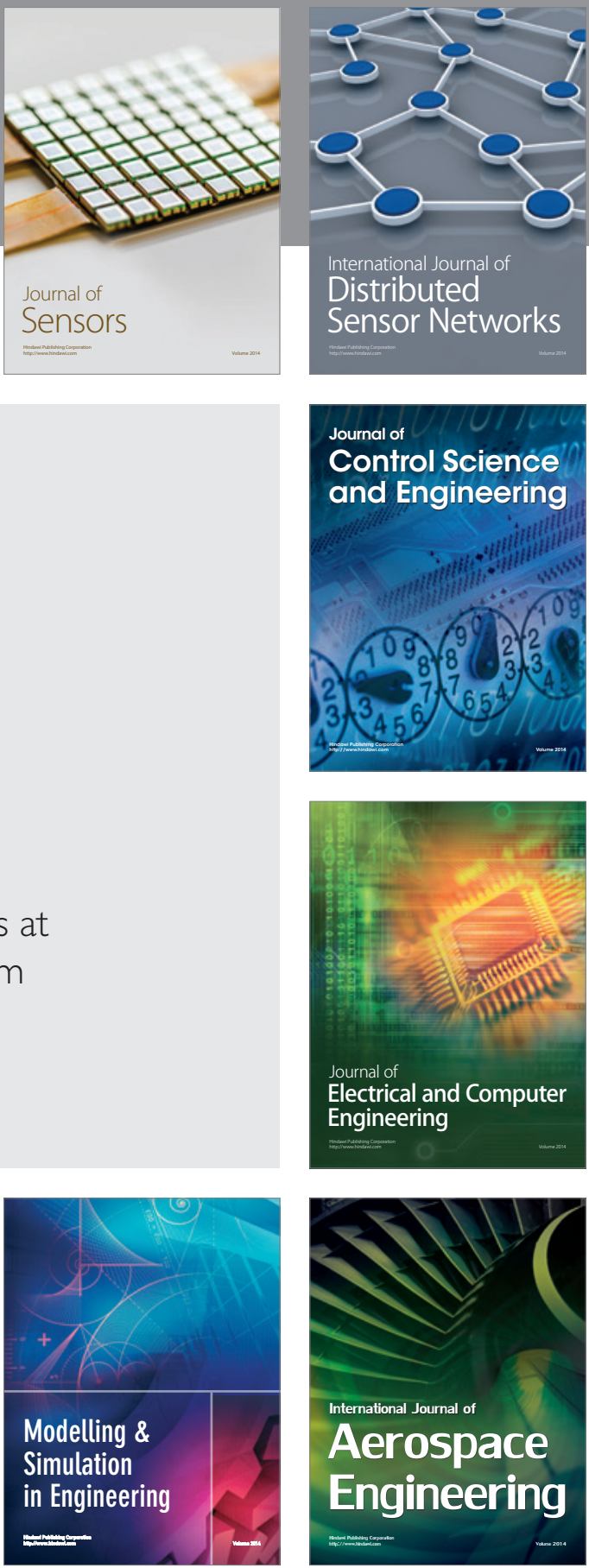

Journal of

Control Science

and Engineering
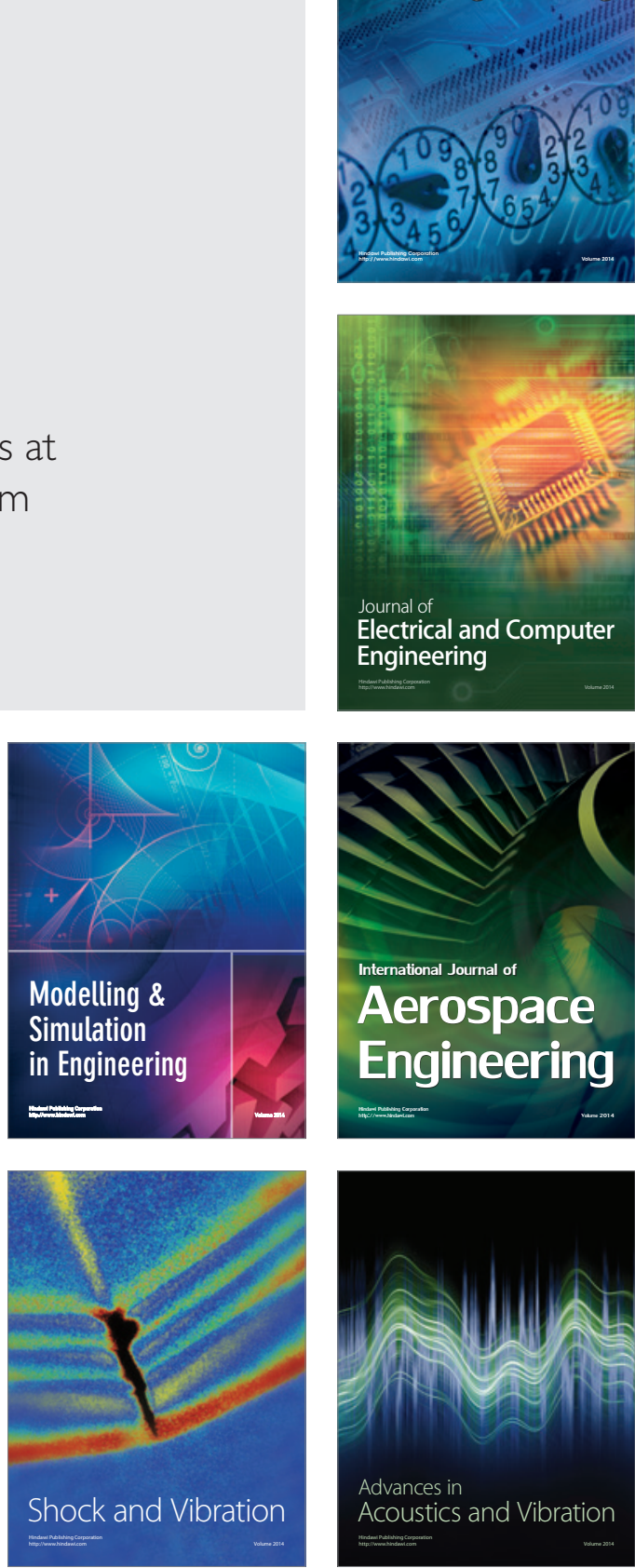